\title{
Correction to: Potentially inappropriate medication in acute hospitalized elderly patients with polypharmacy: an observational study comparing PRISCUS, STOPP, and Beers criteria
}

\author{
Lorena de Agustín Sierra ${ }^{1}$ (D) Jaime Rodríguez Salazar ${ }^{2}$ - Ana Belén Jiménez-Muñoz ${ }^{3}$. \\ María Jesús Molina Hernández ${ }^{2}$ • Paloma Bermejo Bescós ${ }^{4}$ • Irene Iglesias Peinado ${ }^{4}$ - Benito García Díaz ${ }^{1}$
}

Published online: 4 February 2021

(C) Springer-Verlag GmbH Germany, part of Springer Nature 2021

\section{Correction to: European Journal of Clinical Pharmacology https://doi.org/10.1007/s00228-020-03022-8}

Due to an error during production, some in-text and most of the bibliography list citations were not correctly displayed in the original previous online version of the article and have now been corrected.

The original article has been corrected.

Publisher's note Springer Nature remains neutral with regard to jurisdictional claims in published maps and institutional affiliations.

The online version of the original article can be found at https://doi.org/ $10.1007 / \mathrm{s} 00228-020-03022-8$

Lorena de Agustín Sierra

lorena.deagustinsierra@gmail.com

Jaime Rodríguez Salazar

rodriguezsalazarjaime@gmail.com

Ana Belén Jiménez-Muñoz

anabelen.jimenez@salud.madrid.org

María Jesús Molina Hernández

mmolinahernandez@salud.madrid.org

Paloma Bermejo Bescós

bescos@farm.ucm.es

Irene Iglesias Peinado

ireneig@ucm.es
Benito García Díaz

bgdiaz@salud.madrid.org

Servicio de Farmacia, Hospital Universitario Severo Ochoa, Avenida de Orellana, s/n., Leganés, Spain

2 Servicio de Geriatría, Hospital Universitario Severo Ochoa, Avenida de Orellana, s/n., Leganés, Spain

3 Servicio de Medicina Preventiva, Hospital Universitario Severo Ochoa, Avenida de Orellana, s/n., Leganés, Spain

4 Facultad de Farmacia, Servicio de Farmacología y Farmacognosia, Spain, Universidad Complutense de Madrid, Avenida Plaza de Ramón y Cajal, s/n, 28040 Madrid, Spain 